\title{
LETTERS
}

\section{Deeper Problems in the Marketing of Drugs}

To the Editors:-Kudos to Drs. Schiff and Norsigian for an eloquent summary of the real and potential harm to our patients of the pervasive influence of pharmaceutical marketing in health care and patient safety ${ }^{1}$. Patients and providers alike are inundated on a daily basis by attractive advertisements and (often) attractive pharmaceutical representatives whose primary purpose is to promote sales often under the guise of education. I do not disagree fundamentally with any of the author's recommendations for improving this situation, but they should have gone further by insisting that we as physicians must be more skeptical and more scrupulous in doing our homework before prescribing the "latest and greatest" medications being touted in the media or by local pharmaceutical representatives. Most of us know that it is relatively uncommon for any new medication to be so overwhelmingly superior to an older (and often less expensive) medication with an established track record of efficacy and safety that a rapid change in prescribing practices is justified. Primum non nocere-above all do no harm-is one of those axioms often cited but less frequently practiced. We should remember this admonition. My usual response to patients who request a prescription for a novel or new medication is that I tend to be a late adopter when it comes to drugs in particular. The vast majority are reassured when I explain to them that there are enough high profile examples where downstream risks were found well after a medication has been widely

Published online October 13, 2010 prescribed to justify what one of my patients jokingly referred to as the "Canadian" style of practice. All of the accrediting bodies in undergraduate, graduate, and continuing medical education have recognized the potential harms of unfettered pharmaceutical industry access to learners across the spectrum of medical education and have crafted increasingly strict guidelines for such interactions. In the new consumer-driven world in which we live and practice, physicians must exercise caution, responsibility, and knowledgeable authority in talking to patients about the "best and safest treatment." One might even go so far as to say that it is-at least sometimes-a matter of life or death.

Michael R. Grey, MD, MPH, Hospital of Central Connecticut, 100 Grand Street, New Britain, CT 06050, USA (e-mail: mgrey@thocc. org).

\section{REFERENCES}

1. Schiff G, Norsigian J. Estrogen implants: embodiments of deeper problems in the marketing of drugs. JGIM. 2010;25(9):893-94.

J Gen Intern Med 26(1): 12

DOI: $10.1007 / \mathrm{s} 11606-010-1531-6$

(C) Society of General Internal Medicine 2010 